\title{
Research on the Innovation and Development of "Time-honored Brand" Enterprises of Traditional Soybean Products in Changsha
}

\author{
Shijun Yuan \\ Hunan Vocational College of Modern Logistics \\ Changsha, China 410131
}

\author{
Jianhua Chen* \\ Hunan Vocational College of Modern Logistics \\ Changsha, China 410131 \\ *Corresponding Author
}

\begin{abstract}
In recent years, the soybean products' industry in China has developed rapidly. The traditional soybean products' industry has a profound influence in the industry in Changsha, China. This article starts with the development status of soybean products' industry, problem analysis, and development prospects, and discusses the contents and objectives of the innovative development of the time-honored brands of soybean products in Changsha.
\end{abstract}

Keywords—soybean products; innovation; research

\section{INTRODUCTION}

This research is developed in order to effectively solve the problems existing in current circulation of "time-honored" soybean products' enterprises in Changsha, such as the cold chain circulation system of soybean products has not yet been formed, the cold chain facilities and equipment in circulation are insufficient, the technology is backward, and the level of logistics informationization in circulation is low and to promote the sustainable development of the soybean products' industry.

\section{The Current Status of SOYbean Products}

Due to its rich nutrition and low price, soybean products have always been one of the "main characters" in the "vegetable basket" project of large and medium-sized cities, which is getting more and more attention. In recent years, the soybean products industry in China has entered a new stage of development. Soybean products' output has increased steadily and products' variety has continuously increased; products' quality has gradually improved; the industrialization of soybean products' industry has accelerated; corporate brand awareness has been strengthened, and industry management has been gradually on the right track.

\section{A. The Industry Continues to Upgrade and the Industry Is Booming}

The market continues to expand, variety continues to increase, and quality steadily increases. Since the "health" function of soybean products is constantly being recognized, the consumption of soybean products in China is heating up. (2) The market access system has been implemented, urban soybean products' market was rectified, and workshop-type production was gradually standardized. (3) The number of large-scale enterprises has increased, the speed of industrialization has accelerated, the brand awareness has strengthened, and large-scale and brand-based companies have risen rapidly.

\section{B. The Existing Problems in the Development of Soybean Products Industry}

1) The backward cold chain circulation infrastructure and technology restrict the development of soybean products industry: The three important links in the cold chain construction of soybean products: cold storage of the products, transportation of the products and air-conditioner accessories for products' sale terminals require a large amount of funds, and the construction of a relatively complete cold chain system for soybean products will cost about RMB 5 million yuan. Due to the large input costs of cold chain infrastructure construction and equipment for soybean products, many small and medium-sized enterprises have no capital to invest in cold chain, which affects the quality and freshness of current soybean products and the quality and safety of products, and restricts the development of soybean products' industry.

2) The backward production technology and management level restrict the development of soybean products' industry: The production concentration of soybean products is relatively low, with small enterprises accounting for the vast majority, and the small scale of production, which has affected the level of industrialization of soybean products to a certain extent, and has also affected the quality of enterprises and the quality of products. Sampling in the market shows that the qualified rate of production of soybean products is still relatively low, and a large number of small-sized soybean products' manufacturers have hit the market. In the consumer inertia thinking, small soybean products manufacturing enterprises have dirty, uneven environment and poor equipment in their processing sites, and they do not have the basic conditions for food production and processing.

3) The food safety situation of soybean products remains severe: At present, China's relevant departments have a 
relatively large degree of management of the production of soybean products. However, because small workshops are relatively dispersed and concealed, they are difficult to manage in place and the safety production situation is relatively serious. In the circulation field, there are many kinds of soybean products, but there are fewer products with core competitive advantages. The competition is fierce, price gap between products is large, and the vicious competition is serious.

\section{THE NECESSITY OF INNOVATIVE DEVELOPMENT}

\section{A. Innovative Development Is in Line with National Policies and Industrial Development Plans}

In the overall thinking on the structural adjustment of the national food industry, it is proposed to focus on the development of convenience foods, green foods, and traditional foods. At the same time, we must open up the "three green project" (that is to open green channels, cultivate green markets and provide green consumption) during production and sales. The sustainable and rapid development of the national economy and the advancement of urbanization have created a huge demand for the development of the traditional soybean product and food industry. At the same time, with the acceleration of the global economic and regional economic integration process, it has created conditions for China's food industry to allocate resources and expand markets in a broader context.

\section{B. The Need to Build a Two-type Society}

At present, the country regards food safety and dietary health as the primary task of "guaranteeing and improving people's livelihood" in the construction of two-type society. The time-honored brand of traditional soybean products are mainly dried soybean products, which are made of highquality raw materials and advanced technology to provide people with green and safe table foods. As the key work of ensuring and improving people's livelihood, food safety and dietary health is the fundamental starting point and foothold of accelerating the transformation of the economic development pattern, which is the need in the construction of two-type society.

\section{Project Construction Is the Requirement to Strengthen the Soybean Products Industry}

According to data provided by the Changsha City Soybean Products Association, there are currently nearly 500 soybean product manufacturers in Changsha, but there are only about 20 companies that have health licenses, business licenses, and QS certifications. Others are self-employed, black workshops, located in suburban areas such as Lituo and Dongtundu, with backward technology, obsolete equipment, and without guarantee of food safety. Therefore, it has become a top priority to cultivate several large-scale soybean processing enterprises with a wide range of radiation, strong driving force, and high technology level. The traditional and old-fashioned soybean products enterprises are innovating and developing, introducing advanced complete soybean products processing equipment, creating a public service base for circulation processing, centralizing and integrating the urban soybean products processing households, standardizing management, and concentrating processing, which is conducive to promoting the development of Changsha soybean products' industry better and faster.

\section{MARKET PROSPECT}

At present, the daily consumption of Changsha Tofu and Xianggan is about 100 tons. According to industry forecasts, the demand for soybean products in Changsha will maintain an annual growth rate of $8 \%-10 \%$, and the demand for soybean products will continue to rise. With the economic and social development, the living standards of residents have been increasing, and the sales volume of soybean products in Changsha has been in short supply. After the rural market is fully developed, demand for soybean products will further increase. Therefore, Changsha City puts the business of soybean products into the "safety project" of foods, and attaches great importance to food safety in the field of soybean products. According to market research, among the 100 tons of daily consumption of Changsha tofu and Xianggan, the regular manufacturers only produced about 20 tons. The others are produced by small workshops and black workshops. At present, the dried beans of time-honored brand soybean products only have a production volume of 2,000 kilograms per day, and only 3,000 kilograms of soybean products. As a result, soybean products consumption has a great market potential.

\section{CONTENTS AND OBJECTIVES OF INNOVATIVE DEVELOPMENT}

\section{A. Main Content of the Innovative Development}

Changsha traditional time-honored brand of soybean products enterprises can make innovative use of the Internet of things technology to create integrated, intelligent distribution service systems for the production, sales, warehousing and distribution, to realize the whole process monitoring and traceability of the circulation of soybean products, so that "sources can be traced and directions can be verified". Its specific construction includes: (1) "safety soybean products" circulation processing public service base; (2) "safety soybean products" e-commerce trading platform; (3) time-honored brand "safety soybean products" terminal outlets; (4) "safety soybean products" circulation security monitoring and traceability platform.

1) "Safety soybean products" circulation processing public service base

a) Construction objectives: Based on meeting the requirement of time-honored enterprises' own soybean products circulation and processing need, the construction of the public service base for circulation processing with "safety soybean products" is oriented to the soybean products industry enterprises in Changsha, providing them with circulation processing, finished products storage and distribution services to build a soybean circulation and processing base with the largest scale, the largest number of clustered soybean products, the most advanced facilities and 
equipment, and the strongest distribution service capability in Changsha.

b) Construction contents: "Safety soybean products" circulation processing public service base construction project innovatively upgrades and increases the quality of the enterprises, to build it as a soybean products enterprise for the entire Shangsha and provide them with soybean products' circulation processing, finished products storage and distribution services base.

\section{- Modern soybean circulation processing center}

The project will build a modern soybean products circulation and processing center to meet the needs of the enterprises' own and other soybean products industry circulation and processing services. In the process of circulation and processing soybean products, after heat treatment, finished products are generally of higher temperature. Usually companies use natural cooling and fan exhaust cooling. However, in the cold chain system of soybean products, it is required to rapidly cool the product to about $10^{\circ} \mathrm{C}$ when it goes offline so as to enter the cold storage. Therefore, the modern circulation processing center of this project is equipped with cooling equipment, and the cold chain of soybean products circulation process is realized with the help of matching cooling equipment. For example, packaging tofu production line can be equipped with tunnel-type cold water or ice water soaking spray line, while bulk products can be equipped with tunnel-type air circulation cooling line. In this way, by connecting the cooling device to the production line, the product can be quickly and effectively precooled to the required temperature from the initial high temperature state.

\section{- Cold chain logistics distribution center}

In the storage chain, the former soybean products are generally stored in a ventilated, dry and clean environment. However, in the cold chain system, it is required that the precooled product be placed in a low-temperature warehouse to ensure the quality of the product. Therefore, based on its own production scale and the needs of the soybean industry in Changsha, it follows the principles of rationality, adaptability, advancement, economy, and ease of cleaning to build a cold chain logistics distribution center for soybean products of enough areas. Since the storage of soybean products is a key part of the entire cold chain system, enterprises are equipped with refrigeration equipment when they build cold storage facilities.

The whole cold chain logistics distribution service system focuses on the logistics distribution efficiency of the timehonored brand food city to achieve "seamless integration" of time-honored brand food production and consumption. In a more efficient, safe and nutritious way, time-honored brand foods are delivered to consumers.

The time-honored brand food logistics distribution system also has nature of "publicity", "sociality", and "openness". Not only can it provide sorting and delivery services for timehonored brand foods, but also can it provide distribution services for companies that also have distribution needs. At the same time, if necessary, it can also absorb social cold storage and refrigerated truck resources for the service of the timehonored brand.

Vehicle-mounted Beidou positioning system will be installed on distribution vehicles to adopt a delivery mode that will be scheduled at regular intervals. Scheduled route distribution, set the arrival schedule on the determined route and delivery on schedule. Customers can pick up at the required place and time; delivery requirements can be made according to the specified route and time; distribution efficiency can be improved, convenient for residents' consumption and improving the quality of life of all residents.

\section{2) Construction of "safety soybean products" $e$ -} commerce trading platform

a) Construction objectives: "Safe Soybean Products" ecommerce trading platform is based on building an ecommerce trading platform for soybean products' manufacturers, distribution companies, consumers, and relevant government departments, incorporating organically with upstream and downstream companies and institutions that distribute soybean products and make it a collaborative information support system.

The platform is aimed at small and medium-sized soybean products enterprises, providing information of raw materials supply and demand for production enterprises, online goods sales and other e-commerce services; the platform provides ecommerce and enterprise information management services for registered enterprises, reducing the cost of information construction for enterprises, supporting enterprises supply chain management and providing a variety of data interfaces, seamlessly integrating the enterprises' business activities and operational activities to meet the enterprises' collaborative management.

As an open, transparent, and common e-commerce platform, it provides differentiated and transparent services to soybean products' manufacturers, soybean products' distributors, third-party logistics enterprises, and end users, and can meet the needs of different users.

The platform uses advanced digital watermark anticounterfeiting technology, electronic payment technology, information security technology and security authentication technology.

b) Construction contents: The structure of the ecommerce transaction platform of "safety soybean products" adopts the three-layer structure mode, that is, data information layer, service management layer and user application layer.

\section{- Data information layer}

The data information layer of the "safety soybean products" e-commerce platform is to collect, organize, store, update, and maintain relevant data on all aspects of the circulation of soybean products, and to perform corresponding access rights management.

\section{- $\quad$ Service management layer}

The service management layer of "safety soybean products" e-commerce platform is based on the soybean 
products trading information application platform of the data information layer. Between the two layers, a common information platform for circulation is used as an interface, and Internet technology, EDI systems, or mobile communication technologies are used. This layer mainly includes basic information service platform, circulation operation management platform, circulation enterprises' management platform, circulation supply and demand trading platform and trading decision analysis platform. Platform users can get corresponding logistics services by connecting to the web site of the corresponding information platform through the Internet.

- User application layer

The e-commerce platform faces various types of distribution enterprises and enterprises in the circulationrelated supply chain, the system platform adopts identity authentication in the system platform to hierarchically provide different levels of system interaction interfaces and communication service mechanisms; supports data exchange and function calls with other related systems so that the platform has a certain degree of scalability. The platform also implements relevant system security measures to ensure the security of the network, related databases, and various application systems. Platform users can easily connect to various destination information platform sites via the Internet to obtain information about related platforms. Through the ecommerce technology, related circulation business operations are performed, thereby improve its processing efficiency.

3) Construction of time-honored brand "safety soybean products" terminal outlets

a) Construction objectives: During the construction period of this project, it is expected to build 100 terminal retail outlets for time-honored brand soybean products, construct a complete distribution system for time-honored brand soybean products, adopt modern monitoring and tracing technology, implement a strict soybean products safety management system, and create an end-use place for soybean products that allow consumers to rest assured.

b) Construction contents: The construction of terminal retail outlets for the time-honored brand bean products will use community stores and supermarket counters as network terminals, organically combining B2C online shopping platform with $3 \mathrm{G} /$ community function, from point to line, linking into a network, forming a highly coordinated business network with offline market and online market. Use a modern management information system to unify the processing of information data such as customers, products, distribution, and inventory within the network. Relying on the modernized circulation processing public service platform of the enterprise, the branch nodes of the operating network can carry out low-cost and high-efficiency logistics distribution and finally, it will be built into an integrated soybean products' distribution network covering the Changsha area with fast response, unified management, unified standards, and unified service.

4) Construction of "safety soybean products" circulation service platform a) Construction objectives: "Safety soybean products" circulation security monitoring and traceability platform construction aims to realize the integration of logistics, business flow, capital flow and information flow in the whole process of soybean products' circulation through a large data concentration method, integrate soybean products' circulation process positioning information and real-time temperature control information, safeguard the nutritional preservation of time-honored brand food circulation, better provide society with high quality "rest assured soybean products", and satisfy the requirements of the consumers.

b) Construction contents: The time-honored brand soybean products are particularly sensitive to temperature changes and have stringent temperature control requirements for their transportation and storage. To realize the perfect service for customers, the time-honored brand must provide a convincible, reliable, controllable and manageable whole process monitoring system for circulation. Such as the temperature and humidity range of storage, the temperature of the refrigerator, the location of the vehicle, the delivery of the transported goods, etc. are all key management tasks, especially the temperature monitoring.

According to the industry specificity of the cold chain circulation of time-honored brand foods, through the application of new technologies such as Beidou navigation system, geographic information system GIS, bar code technology, RFID radio frequency technology, and Internet of things temperature control technology, combining with the Internet of things, building a cold chain logistics integrated public information monitoring platform, supervise and manage the whole process of cold chain circulation.

The monitoring system for the design of the time-honored brand logistics information platform needs to implement the monitoring and management of the entire cold chain. The data can be shared dynamically with the customer's existing business system and network, which will offer a unified network platform and application service platform for all parties to provide dynamic information query management, and management and customers can transparently review and monitor the operation status of the time-honored brand. The management staff can also monitor the real-time operation status of the time-honored brand food cold warehouses at various monitoring points through the camera.

\section{CONCLUSION}

Through innovative development, Changsha traditional time-honored brand soybean products enterprises have built "safety soybean products" circulation processing public service base, "safety soybean products" e-commerce trading platform, time-honored brand "safety soybean products" terminal outlets, "safety soybean products" circulation security monitoring and traceability platform, and so on, constructed a "safety soybean products" circulation service platform with a rational layout, complete service functions, convenience for the people, safety and security of the soybean industry in Changsha area, which will promote the development of soybean products' industry in Changsha. 


\section{REFERENCES}

[1] Fu Biao. Polishing the old name is a success in innovation. Entrepreneur Daily.2017. 付彪. 擦亮老字号 功在传承胜在创新. 企业家日报.2017

[2] Zhai Youzi. Exploration of Problems and Countermeasures in the Development of Cold Chain Logistics for Fresh Soybean Products[J]. Estate and Science Tribune .2015. 翟优子. 生鲜豆制品冷链物流发展 问题与对策探索 $[\mathrm{J}]$. 产业与科技论坛.2015

[3] Zhou Jianhua. Analysis of Cold Chain Logistics Development Strategies for Fresh Soybean Products[J]. Science \& Technology Economics Guide.2017. 周建华. 生鲜豆制品冷链物流发展对策分析 [J]. 科技经济导刊. 2017

[4] Sun Wei. Discussion on Development Strategy of Fresh Agricultural Products Based on E-commerce Platform [J]. Journal of Commercial Economics.2017. 孙苪. 基于电子商务平台的生鲜农产品发展策略探 讨 $[\mathrm{J}]$. 商业经济研究.2017

[5] Zhang Chunrong. The existing problems and development countermeasures of China's agricultural products e-commerce platform[J]. Agricultural Economy.2017. 张纯荣. 我国农产品电子商 务平台存在的问题及发展对策研究[J].农业经济, 2017 . 